\title{
Influencing Change: Preparing the Next Generation of Clinicians to Practice in the Digital Age
}

\author{
Cynthia Baker, Maureen Charlebois, Harold Lopatka, Geneviève Moineau and Jennifer Zelmer
}

\section{Introduction}

From connecting with friends and family to sophisticated supply chain management, digital solutions have fundamentally changed many aspects of our lives. The ways that we seek and receive healthcare are also undergoing profound transformation, a change that it is essential that the next generation of clinicians be prepared for and optimize. As Duncan Sinclair pointed out in a recent editorial in this journal (Sinclair 2014):

"While health professional education doesn't need 'destruction,' it does need, and quickly, to consider creatively how to do its job more effectively and efficiently in this new digital world."

In partnership with Canada Health Infoway (Infoway), Canada's faculties of medicine, nursing and pharmacy embraced this challenge in 2011 when they agreed to focus on how to better prepare students to practice in modern, technology-enabled, clinical environments. The specific goals of this program were to:

- Ensure that clinicians-in-training are ready to practice in, and gain value from, an information and communications technologies (ICT)-enabled environment when they graduate; and

- Integrate concepts and expectations related to the use of ICT in practice into curricula design and educational processes.

The focus is not on basic digital competencies, such as navigating websites or using a tablet, but rather on how to use health informatics to enhance patient- and family-centred care.

Each of the professions began with understanding the current state of education across the country and then reached a consensus on important competencies for future professionals. They also gathered and developed teaching and learning resources aligned with the competencies to strengthen learning and teaching for faculty and students. New awards were created to recognize faculty and students who demonstrate exceptional leadership and commitment to e-Health and informatics in education curriculum and to promote and showcase new innovative tools supporting health informatics. See Table 1 for links to these resources.

Building on this foundation, new initiatives are now underway to support faculty in preparing future clinicians to understand and practice in a digital environment consistent with the core competencies that have been established (see Table 1 for details and links to reference documents). These efforts are taking place both within disciplines and across them, leveraging the interprofessional relationships developed in the first phase of the initiative.

\section{Medicine}

The Association of Faculties of Medicine of Canada (AFMC) and Infoway (2015) launched a Physicians-in-Training project in 2011, with the overall objective of improving clinical practice and patient care by supporting medical students and residents in their adoption and use of digital health technologies. A Leadership Committee with academic e-Health experts from seven provinces steered the project. They first undertook an environmental scan and key informant interviews to assess undergraduate e-Health curricula at Canadian faculties of medicine. It identified disparate e-Health training in the medical curricula and the absence of criteria to address e-Health in medical curricula nationally.

The resulting recommendations drove the publication of the first ever national e-Health Competencies for Undergraduate Medical Education. They were aligned with the broader CanMEDS 2015 Physician Competency Framework. This next-generation competency-based medical education model under the auspices of the Royal College of Physicians and Surgeons of Canada describes the knowledge, skills and abilities that specialist physicians need for better patient outcomes. 
TABLE 1.

Initiatives Underway

\begin{tabular}{|c|c|c|c|}
\hline & Medicine & Nursing & Pharmacy \\
\hline Project background & $\begin{array}{l}\text { AFMC-Infoway Physicians in } \\
\underline{\text { Training Project Review }}\end{array}$ & $\begin{array}{l}\text { CASN-Infoway Nurses in Training } \\
\underline{\text { Project Review }}\end{array}$ & $\begin{array}{l}\text { AFPC-Infoway Pharmacists in Training } \\
\text { Project Review }\end{array}$ \\
\hline Competencies & $\begin{array}{l}\underline{\text { eHealth Competencies for }} \\
\underline{\text { Undergraduate Medical Education }}\end{array}$ & $\begin{array}{l}\frac{\text { Nursing Entry-to-Practice }}{\text { Competencies for Registered }} \\
\underline{\text { Nurses }}\end{array}$ & $\begin{array}{l}\text { Pharmacy Informatics Entry-to-Practice } \\
\text { Competencies for Pharmacists }\end{array}$ \\
\hline Teaching and learning resources & $\begin{array}{l}\underline{\text { Canadian Healthcare Education }} \\
\underline{\text { Commons }} \\
\underline{\text { Environmental Scan of eHealth in }} \\
\underline{\text { Canadian Undergraduate Medical }} \\
\underline{\text { Curriculum }}\end{array}$ & $\begin{array}{l}\text { Nursing Informatics Inventory: } \\
\text { Existing Teaching and Learning } \\
\text { Resources } \\
\text { Nursing Informatics Teaching Toolkit }\end{array}$ & $\begin{array}{l}\text { Informatics for Pharmacy Students } \\
\underline{\text { e-Resource }}\end{array}$ \\
\hline
\end{tabular}

The project also enabled AFMC to propose a new accreditation standard related to e-Health for Canadian medical schools.

In addition, the project engaged clinician educators, informatics experts, deans, students and residents in the creation and sharing of new e-learning resources to support the integration of digital health concepts into medical education curricula. Student/faculty teams developed 33 virtual patient cases by incorporating the use of digital health to improve patient care, the top three of which each year received national awards. A rich set of 185 resources was also contributed to an online community hosted through the Canadian Healthcare Education Commons.

This work and broader contributions were honoured annually at the Canadian Conference on Medical Education. Faculty members who demonstrated exceptional leadership and commitment to e-Health and informatics in the medical education curriculum received national awards.

\section{Nursing}

The Canadian Association of Schools of Nursing (CASN) and Infoway (2015) have been working together to help new nursing graduates enter the workplace able to practice effectively in the increasingly electronic world of healthcare delivery, thereby improving care delivery and patient outcomes. This initiative integrates concepts and expectations related to the use of digital health in practice into the curricula design and educational processes of the Schools of Nursing. The goal of the project is to develop a culture within nursing education in Canada that embraces the integration of nursing informatics in curricula and professional practice.

An early focus was to gain consensus on Nursing Informatics Entry-to-Practice Competencies for Registered Nurses. They outline the knowledge and skills that should be acquired by registered nurses over the course of their undergraduate education. Each is accompanied by a list of indicators, and together they are intended to provide direction for curriculum development. The competencies also led to strengthened e-Health content in CASN's Accreditation Standards.
Through the consultation with experts in nursing informatics, education, practice and policy, as well as CASN's 91-member schools, educational resources were created to support the nursing faculty in adopting and integrating the competencies. A Teaching Toolkit outlines key concepts and learnings, summarizing information faculty need to teach each of the nursing informatics competencies. It also provides teaching tools (e.g. presentations, case studies and discussion questions) that faculty can easily integrate into existing lesson plans. In addition, an inventory of available Canadian and international teaching and learning resources aims to increase the capacity of nurse educators to teach nursing informatics at an undergraduate level. It focuses particularly on resources that offer guidance on the integration of nursing informatics into curricula and practice. Collectively, the resources have already been downloaded more than 8,300 times.

Furthermore, faculty and student awards were designed to promote the adoption and integration of nursing informatics into nursing education and professional practice. Faculty were recognized for exceptional leadership and commitment to e-Health and informatics in nursing education. The focus of the Student E-Health Leadership Award was to recognize excellence in the adoption and use of digital health among Canadian nursing students and highlight the role of digital health solutions in enabling evidence-based, patient-centred care.

Promising changes are beginning to emerge. A 2014 survey found that $74 \%$ of nursing faculty are somewhat to very confident in teaching nursing informatics/e-Health. Likewise, 64\% of faculty report having incorporated informatics into their curriculum, and $73 \%$ of respondents reported "threading" informatics throughout their curriculum.

\section{Pharmacy}

The objective of the joint Association of Faculties of Pharmacy of Canada (AFPC) and Infoway (2015) project is to better prepare pharmacy students to practice in modern, technology-enabled 
environments by developing and integrating concepts and expectations related to the use of digital health into curricula design and educational processes.

The first phase focused on developing and validating an informatics competency framework for undergraduate education. The Pharmacy Informatics Entry-to-Practice Competencies for Pharmacists were based on an extensive literature review and review of existing relevant competency frameworks. The competencies were then validated and prioritized through a survey of pharmacy stakeholders and key informant interviews. The resulting framework consists of foundational skills on device and application use and three competencies (information and knowledge management, professional and regulatory accountability and information and communication technologies) with 31 corresponding indicators. These competencies served as a basis for development of the program content matrix, which, in turn, informed the national educational program that is being integrated into the undergraduate pharmacy curricula in Canadian Universities.

The complementary Informatics for Pharmacy Students e-Resource is a national online education program. Although primarily directed at pharmacy students, it is also expected to be of value to practicing pharmacists, pharmacy technicians and other healthcare professionals. Written by Canadian pharmacy faculty and clinicians with participation from upper-year pharmacy students selected through a competitive award process, the modules within the e-Resource can be integrated by faculty into existing courses or used on a stand-alone basis. The e-resource uses innovative learning activities including virtual patients, polls, discussion forums and self-assessment quizzes.

\section{Moving Ahead}

Canada is home to world-class medical, nursing and pharmacy schools whose educators and students recognize the value and potential of digital health to improve health and healthcare. With the groundwork laid for each of the three participating professions, the next stage of efforts is supporting faculties through the transformation process. Building on a model that has proven successful for practicing clinicians, Infoway, AFMC, AFPC and CASN recently launched faculty peer leader networks. These networks aim to create a collaborative and engaging environment that provides support and mentorship for the academic community as faculty integrate the competencies and e-resources into their teaching. In addition, new interprofessional awards recognize faculty who work together across disciplinary boundaries to help future clinicians use technology in innovative ways to provide high-quality services with and for patients and families. Individually and collectively, the goal of these efforts is to meet the challenge to the health profession outlined by Duncan Sinclair in his recent article (2014) - the need to "figure out what and how to change to meet the challenges of the digital revolution that is the hallmark of the $21^{\text {st }}$ century." $\mathrm{HQ}$

\section{References}

Canada Health Infoway and Association of Faculties of Medicine of Canada (AFMC). 2015. AFMC-Infoway Physicians in Training - Project in Review: Preparing Medical Graduates to Practice in a Technology-Enabled World. Retrieved July 31, 2015. <www.infoway-inforoute.ca/en/component/ edocman/2727-afmc-infoway-physicians-in-training-project-in-review/ download>.

Canada Health Infoway and Association of Faculties of Pharmacy of Canada (AFPC). 2015. Informatics for Pharmacy Students: Preparing Pharmacy Students to Practice in a Technology-Enabled Environment. Retrieved July 31, 2015. <www.infoway-inforoute.ca/en/component/ edocman/resources/reports/clinical-adoption/2073-pharmacists-intraining-project-in-review-2014? Itemid=101>.

Canada Health Infoway and Canadian Association of Schools of Nursing (CASN). 2015. The Nurses-in-Training Project: Preparing Nursing Graduates for a Technology-Enabled World. Retrieved July 31, 2015. <www.infoway-inforoute.ca/en/component/edocman/2161nursing-in-training-project-in-review/download?Itemid=101>.

Sinclair, D.G. 2014. "It's Time to Revisit Flexner." Healthcare Quarterly 17 (2): 5-6.

\section{About the Authors}

Cynthia Baker, RN, PhD, is the executive director at the Canadian Association of Schools of Nursing.

Maureen Charlebois, $\mathrm{CHE}, \mathrm{RN}, \mathrm{MHSc}, \mathrm{BScN}$, is the chief nursing executive and group director at Canada Health Infoway.

Harold Lopatka, CHE, BSc. Pharm., MHSA, PhD, is the executive director at the Association of Faculties of Pharmacy of Canada and has a clinical academic colleague (adjunct) appointment with the Faculty of Pharmacy and Pharmaceutical Sciences at the University of Alberta.

Geneviève Moineau, MD, FRCPC, is the president and chief executive officer at the Association of Faculties of Medicine of Canada.

Jennifer Zelmer, PhD, is executive vice president at Canada Health Infoway and has an adjunct appointment with the School of Health Information Science at the University of Victoria. She is also the editor-in-chief of Healthcare Policy.

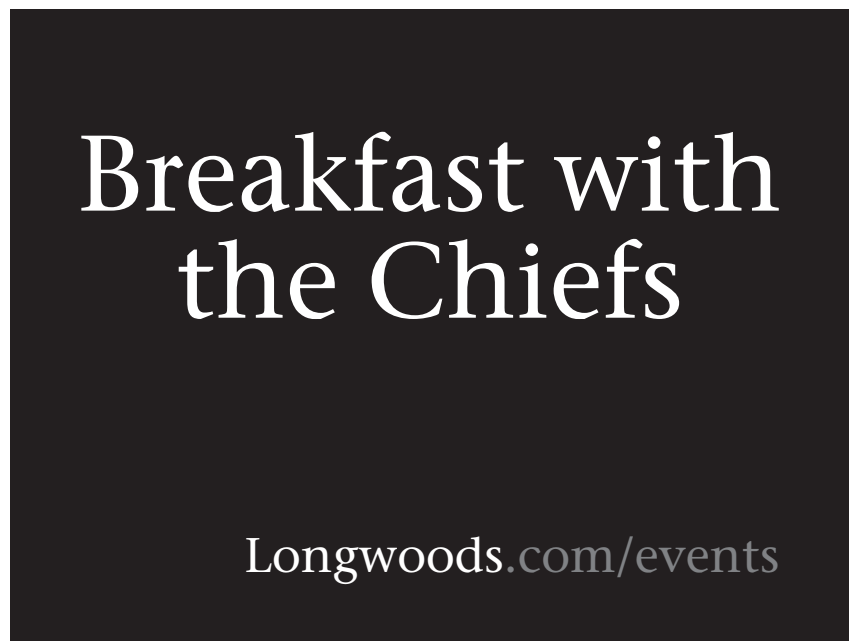

